\title{
Room-temperature direct bonding of diamond and $\mathrm{Al}$
}

Jianbo Liang, Shoji Yamajo, Martin Kuball, Naoteru Shigekawa

\begin{tabular}{|c|c|}
\hline Citation & Scripta Materialia, $159 ; 58-61$ \\
\hline Issue Date & 2019-01-15 \\
\hline Type & Journal Article \\
\hline Textversion & author \\
\hline Rights & $\begin{array}{l}\text { C } 2018 \text { Acta Materialia Inc. Published by Elsevier Ltd.This manuscript version is } \\
\text { made available under the CC-BY-NC-ND } 4.0 \text { License. } \\
\text { https://creativecommons.org/licenses/by-nc-nd/4.0/ } \\
\text { This is the accepted manuscript version. The following manuscript has been } \\
\text { accepted by Scripta Materialia. The article has been published in final form at } \\
\text { https://doi.org/10.1016/j.scriptamat.2018.09.016 }\end{array}$ \\
\hline DOI & 10.1016/j.scriptamat.2018.09.016 \\
\hline
\end{tabular}

Self-Archiving by Author(s)

Placed on: Osaka City University 


\title{
Room-temperature Direct Bonding of Diamond and Al
}

\author{
Jianbo Liang ${ }^{1, *)}$, Shoji Yamajo ${ }^{1}$, Martin Kuball², and Naoteru Shigekawa ${ }^{1}$ \\ ${ }^{1}$ Electronic Information System, Osaka City University, 3-3-138 Sugimoto, Sumiyoshi- \\ $\mathrm{Ku}$, Osaka 558-8585, Japan \\ ${ }^{2}$ Center for Device Thermography and Reliability (CDTR), H. H. Wills Physics \\ Laboratory, University of Bristol, Tyndall Avenue, Bristol BS8 1TL, United Kingdom
}

Direct bonding of diamond and Al is achieved by surface activated bonding at room temperature. The interfacial structures of the diamond/Al bonding interface with annealing at different temperatures are investigated under in-situ annealing in a transmission electron microscope (TEM). An amorphous layer with a thickness of $4 \pm 0.5$ $\mathrm{nm}$ is formed at the bonding interface without annealing, the thickness of the amorphous layer decreases with increasing annealing temperature, the amorphous layer vanished after annealing at $600{ }^{\circ} \mathrm{C}$. No structural defects are observed at the bonding interface with annealing at different temperatures.

*Corresponding author. Tel: 81-6-6605-297. E-mail: liang@elec.eng.osaka-cu.ac.jp (J. Liang) 
Electronic semiconductor devices such as metal oxide semiconductor field effect transistor (MOSFET), bipolar junction transistor (BJT), insulated gate bipolar transistor (IGBT), high electron mobility transistor (HEMT) are extensively used in home electronics, telecommunication, transport, electric grid and numerous other applications. The high operating power density in such devices commonly produces an increase in temperature near the active device region, which would degrade device performance and reliability [1-3]. Therefore, the suppression of the temperature rise is particularly important to increase the operational power density.

Diamond has the highest thermal conductivity among materials and is an ideal material to suppress the rise in the device temperature when integrated with electronic devices. The integration of GaN-based devices and diamond by direct growth and wafer bonding has recently been demonstrated, resulting in improved thermal management and threefold increase in areal power density [4-5]. Devices can be directly mounted onto the heat sink by solder bonding [6] or hydrophilic bonding [7]. For any device, an effective thermal boundary resistance exists between the device and the heat sink, which is a significant thermal barrier for heat transfer from the device to the heat sink. Because the thermal conductivity of the solder materials such as AgSn and AuSn is very low in comparison with that of diamond.

In this work, we directly bonded polycrystalline diamond substrate to aluminum ( $\mathrm{Al})$ by surface activated bonding ( $\mathrm{SAB})$ at room temperature and investigated the structural properties of the bonding interface by transmission electron microscopy (TEM) and energy dispersive X-ray spectroscopy (EDX). In situ observation of microscopic structural changes in a TEM of the bonding interface at various annealing temperatures was carried out within a filament type heating TEM holder. During bonding process, the 
surface of the bonding materials was activated by the irradiation of Ar fast atom beam. We consequently investigated the chemical bonding states of polycrystalline diamond surface without and with Ar irradiation, and with Ar irradiation and annealing at $600{ }^{\circ} \mathrm{C}$ by X-ray photoemission spectroscopy (XPS).

Commercial polycrystalline diamond and $\mathrm{Al}$ were used for our bonding experiments. The size of the diamond and Al substrates are $10 \mathrm{~mm} \times 10 \mathrm{~mm} \times 0.25 \mathrm{~mm}$ and $20 \mathrm{~mm} \times$ $15 \mathrm{~mm} \times 0.25 \mathrm{~mm}$, respectively. Prior to the bonding, the surface of the diamond substrates was polished by chemical mechanical polishing. The averaged roughness of the polished diamond surface and Al substrate surface was measured to be 0.32 and 70 $\mathrm{nm}$, respectively, by using atomic force microscope (AFM). Al and the polished diamond substrates were cleaned with acetone and ethanol in an ultrasonic bath for $300 \mathrm{~s}$, dried under $\mathrm{N}_{2}$, and then set in the vacuum chamber of bonding facility. The background vacuum pressure was kept at $5.0 \times 10^{-7} \mathrm{~Pa}$. The surfaces of the diamond and Al were simultaneously activated by the Ar fast atom beams irradiation with a power of $1.5 \mathrm{kV}$ and $1.5 \mathrm{~mA}$ for $180 \mathrm{~s}$. After the surface activation, they were bonded to each other at room temperature by applying a pressure of $10 \mathrm{GPa}$ for 60 s, i.e. using surface activated bonding (SAB) with more details described in Ref. [8-10]. The structure of the diamond/Al bonding interface was investigated using a TEM (JEM-2200FS) equipped with EDS. The microstructural change of the bonding interface with annealing at different temperatures were investigated by in-situ TEM observation at room temperature under a high vacuum $\left(\sim 1 \times 10^{-5} \mathrm{~Pa}\right)$. The chemical bonding structures of diamond without and with $\mathrm{Ar}$ irradiation, and with Ar irradiation and annealing at $600{ }^{\circ} \mathrm{C}$ were evaluated using XPS (ESCA-3400) with a monochromatic $\mathrm{Mg} K \alpha$ x-ray radiation source.

Figure 1 shows a low magnification TEM image of the cross section of the diamond/Si 
bonding interface without annealing. A straight line could be clearly recognized at the center of the figure, which corresponds to the bonding interface between diamond and Al. It was found that most of the bonding interface is smooth and free of micro-voids and direct bonding of diamond and $\mathrm{Al}$ in the micro scale were achieved.

The cross-sectional TEM images of the diamond/Al bonding interface without and with annealing at 200, 400, and $600{ }^{\circ} \mathrm{C}$ are shown in Figs 2(a), (b), (c), and (d), respectively. As shown in Fig. 2(a), an amorphous layer with a thickness of about $4 \mathrm{~nm}$ was formed at the bonding interface. The thickness of the amorphous layer was reduced from $4 \mathrm{~nm}$ to 3 $\mathrm{nm}$ after annealing at $200{ }^{\circ} \mathrm{C}$. Furthermore, when the annealing temperature increased to $400{ }^{\circ} \mathrm{C}$, the thickness of the amorphous layer was decreased to $2 \mathrm{~nm}$. Finally, the amorphous layer disappeared after annealing at $600{ }^{\circ} \mathrm{C}$. The thickness of the amorphous layer is therefore highly depended on the annealing temperature, which decreased with increasing annealing temperature. There are no structural defects such as cracks observed at the interface with annealing at various temperatures.

EDX mappings of the diamond/Al bonding interface without and with annealing at $600{ }^{\circ} \mathrm{C}$ are shown in Figs. 3(a) and (b), respectively. Comparing the EDX mappings of the different elements, it is evident there is an oxygen rich part at the bonding interface without annealing. The results indicate that there is a thin transition layer formed at the bonding interface, which is composed of $\mathrm{C}, \mathrm{Al}$, and $\mathrm{O}$ elements. The oxygen rich part formed at the bonding interface should be related to the residual oxygen of the vacuum chamber. However, after annealing at $600{ }^{\circ} \mathrm{C}$ no overlap and oxygen rich part were observed at the bonding interface.

The C1s spectra of diamond without and with Ar irradiation, and with Ar irradiation and annealing at $600{ }^{\circ} \mathrm{C}$, and as well as the $\mathrm{C} 1 \mathrm{~s}$ spectrum of diamond that was prepared 
by annealing the diamond/Al bonded sample at $600{ }^{\circ} \mathrm{C}$ and removing $\mathrm{Al}$ substrate are shown in Figs. 4(a), (b), (c), and (d), respectively. The C1s spectrum were fitted by a Gaussian function, after the backgrounds were subtracted using Linear and Shirley's method. As shown in Fig. 4, the C1s spectrum of diamond were decomposed into three peaks, which are attributed to the $\mathrm{sp}^{2}$ and $\mathrm{sp}^{3}$ carbon atoms and the $\mathrm{C}-\mathrm{O}$ bonding state, respectively $[11,12]$. By integrating the area of the decomposed peaks, the peak area ratio of $\mathrm{sp}^{2} /\left(\mathrm{sp}^{2}+\mathrm{sp}^{3}\right)$ was estimated to be $3.4,26.6$, and $1.2 \%$ for diamond without and with Ar irradiation, and with Ar irradiation and annealing at $600^{\circ} \mathrm{C}$, respectively. In addition, the peak area ration of $\mathrm{sp}^{2} /\left(\mathrm{sp}^{2}+\mathrm{sp}^{3}\right)$ in diamond prepared by annealing the diamond/Al bonded sample and removing $\mathrm{Al}$ substrate was estimated to be $2.1 \%$. These results indicate that the portion of the amorphous carbon or graphite increases after Ar irradiation and decreases after annealing at $600{ }^{\circ} \mathrm{C}$. It was found that the $\mathrm{C} 1 \mathrm{~s}$ bonding energy of diamond shifted once to the low energy side after Ar irradiation and recovered slightly after annealing at $600{ }^{\circ} \mathrm{C}$ in comparison with that of diamond without Ar irradiation. These should be attributed to the charging effect and chemical shift [13].

The result of our experiment clearly shows that the amorphous layer formed at the bonding interface without annealing should be induced by the irradiation of Ar fast atom beam, because similar amorphous layer was also observed at the $\mathrm{Si} / \mathrm{SiC}$ [14], $\mathrm{Si} / \mathrm{GaAs}$ [15], and Diamond/Si [16] bonding interface fabricated by SAB. The amorphous layer disappeared after annealing at $600{ }^{\circ} \mathrm{C}$ due to the recrystallization of the amorphous layer in a high temperature annealing process. The result is consisted with the result obtained by XPS, in which the $\mathrm{sp}^{2} /\left(\mathrm{sp}^{2}+\mathrm{sp}^{3}\right)$ ratio decreased from $26.6 \%$ to $2.1 \%$ after the bonding interface annealing at $600{ }^{\circ} \mathrm{C}$, which is contributed to the decrease of the ratio of the amorphous carbon or graphite. It is worth to note that although the thermal expansion 
coefficient of $\mathrm{Al}$ is larger than that of diamond [17], no structural defects such as cracks were observed at the interface after the bonding interface annealing at $600{ }^{\circ} \mathrm{C}$, which suggest that the diamond/Al bonding interface fabricated by SAB is suitable for connecting the device and the heat sink system.

In summary, Diamond/Al bonding interface was successfully fabricated by SAB at room temperature. The influence of thermal annealing process on the interfacial structure of the bonding interface was demonstrated by In-site TEM observation in a high vacuum. It was found that an amorphous layer with a thickness of about $4 \mathrm{~nm}$ was formed at the bonding interface without annealing, the thickness of the amorphous layer highly depended on the annealing temperature, which decreased with increasing annealing temperature, disappeared after annealing at $600{ }^{\circ} \mathrm{C}$. The $\mathrm{sp}^{2} /\left(\mathrm{sp}^{2}+\mathrm{sp}^{3}\right)$ ratio of diamond surface estimated from the X-ray photoemission spectra increased from $3.4 \%$ to $26.6 \%$ after the irradiation of Ar fast atom beam and decreased from $26.6 \%$ to $1.2 \%$ after annealing at $600{ }^{\circ} \mathrm{C}$, which should be predominantly attributable to the diamond-graphite conversation. These results indicate that the diamond/Al bonding interface fabricated by SAB should be highly useful for connecting diamond and heat sink for high-power application in harsh environments.

Acknowledgments This work was supported by Hirose International Scholarship Foundation, Japan. The authors would like to thank Prof. Hiroki Kurata and Mr. Tsutomu Kiyomura of Kyoto University Microstructural Characterization Platform for fabricating TEM sample and observing the bonding interface.

\section{References}

[1] G. Meneghesso, G. Verzellesi, F. Danesin, F. Rampazzo, F. Zanon, A. Tazzoli, M. 
Meneghini, and E. Zanoni, IEEE Trans. Device Mater. Rel. 8 (2008) 332.

[2] R. Gaska, A. Osinsky, J. Yang, and M. S. Shur, IEEE Electron Device Lett. 19(3) (1998) 89.

[3] A. Sarua, H. Ji, M. Kuball, M. J. Uren, T. Martin, K. P. Hilton, and R. S. Balmer, IEEE Trans. Electron Devices 53(10) (2006) 2438.

[4] H. Sun, R. B. Simon, J. W. Pomeroy, D. Francis, F. Faili, D. J. Twitchen, and M. Kuball, Appl. Phys. Lett. 106 (2015) 111906.

[5] D. Francis, F. Faili, D. Babic, F. Ejeckam, A. Nurmikko, and H. Maris, Diamond Relat. Mater. 19(2) (2012) 1525.

[6] M. Kuznetsov, F. Hakimi, R. Sprague, and A. Mooradian, IEEE Photonics Technol. Lett. 9 (1997) 1063.

[7] Z. L. Liau, Appl. Phys. Lett. 77 (2000) 651.

[8] H. Takagi, K. Kikuchi, R. Maeda, T. R. Chung, and T. Suga, Appl. Phys. Lett. 68 (1996) 2222

[9] J. Liang, T. Miyazaki, M. Morimoto, S. Nishida, N. Watanabe, and N. Shigekawa, Appl. Phys. Express 6 (2013) 021801.

[10] M. M. R. Howlader, T. Watanabe, and T. Suga, J. Appl. Phys. 91 (2002) 3062.

[11] D. Bullutaud, N. Simon, H. Girard, E. Rzepka, and B. Bouchet-Fabre, Diamond Relat. Mater. 15 (2006) 716.

[12] B. Humbert, N. Hellala, J. J. Ehrhardt, S. Barrat, and E. Bauer-grosse, Appl. Surf. Sci. 254 (2008) 6400.

[13] C. D. Wagner, J. Electron Spectrosc. Relat. Phenom. 10 (1997) 305.

[14] J. Liang, S. Nishida, M. Arai, and N. Shigekawa, Appl. Phys. Lett. 104 (2014) 161604. 
[15] J. Liang, L. Chai, S. Nishida, M. Morimoto, and N. Shigekawa, Jpn. J. Appl. Phys. $54(2015) 030211$.

[16] J. Liang, S. Masuya, M. Kasu, and N. Shigekawa, Appl. Phys. Lett. 110 (2017) 111603.

[17] C. Guo, X. He, S. Ren, and X. Qu, Rare Met. 35(3) (2016) 249.

\section{Figure caption}

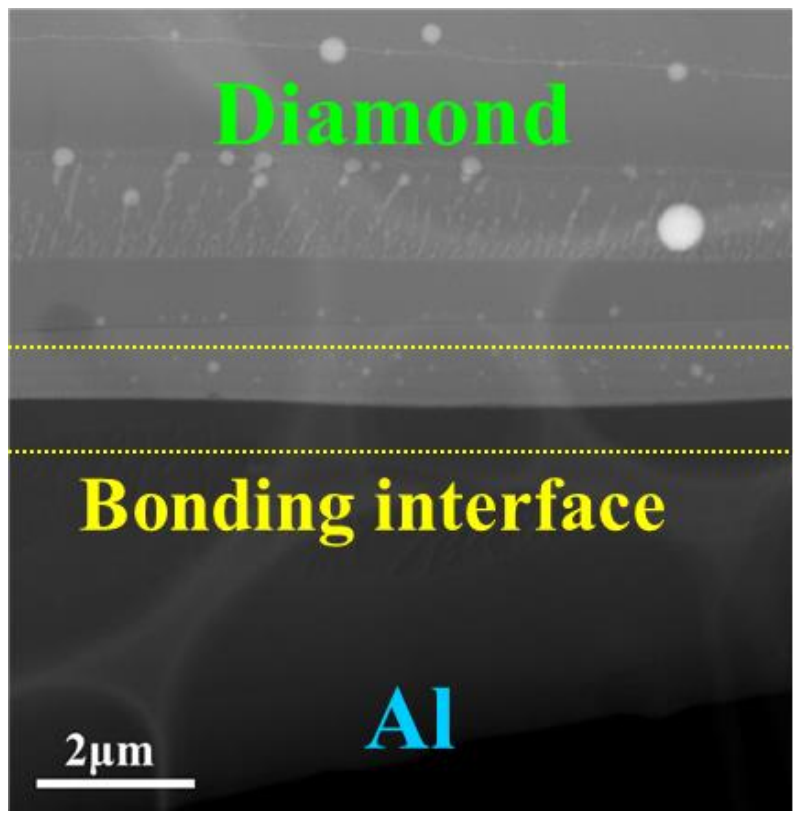

Figure 1 A low magnification cross-sectional TEM image of the diamond/Al bonding interface without annealing. Note that the observed white spherical objects were Ga contaminations caused during TEM sample fabrication by focused ion beam (FIB). 

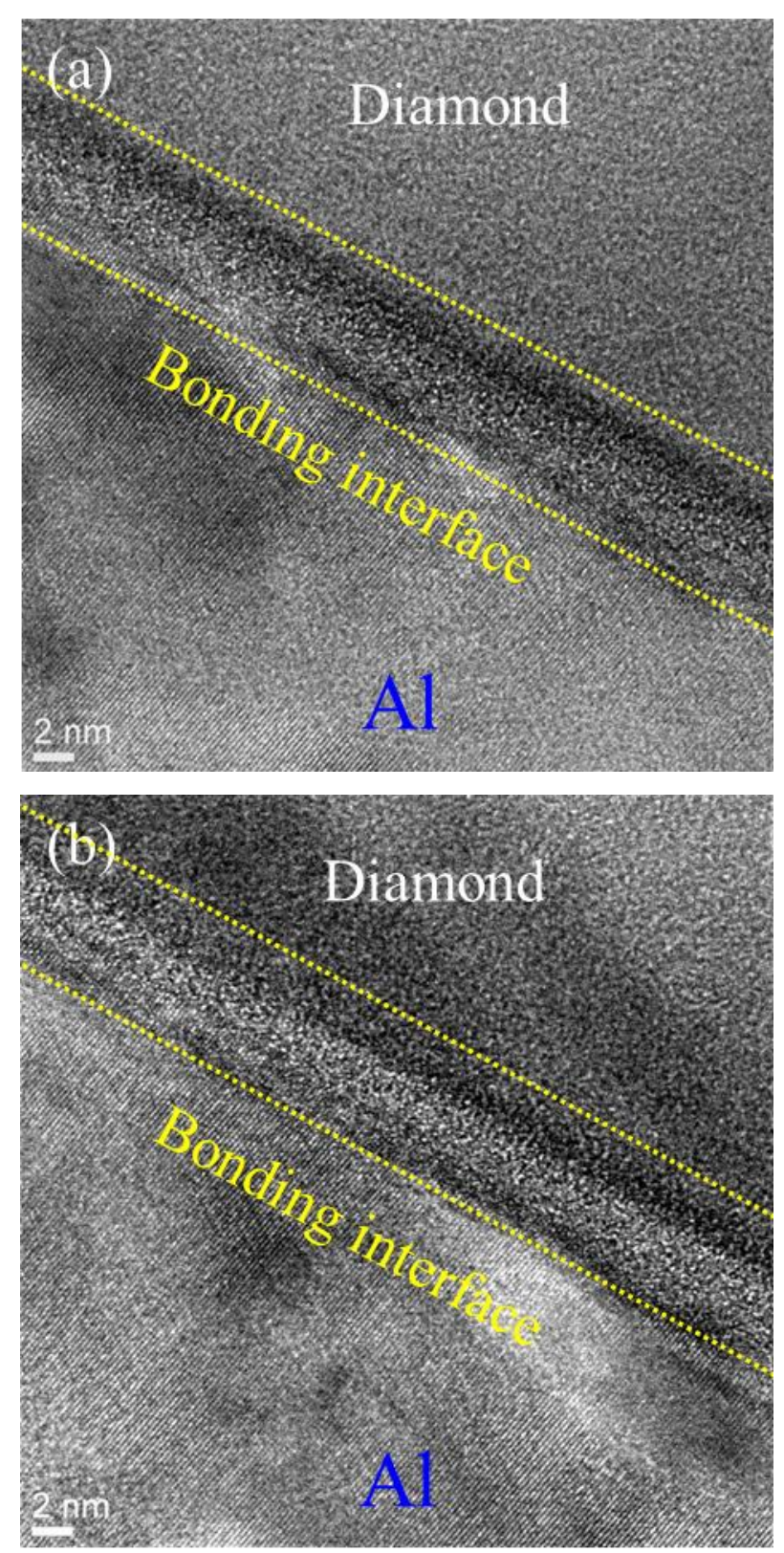

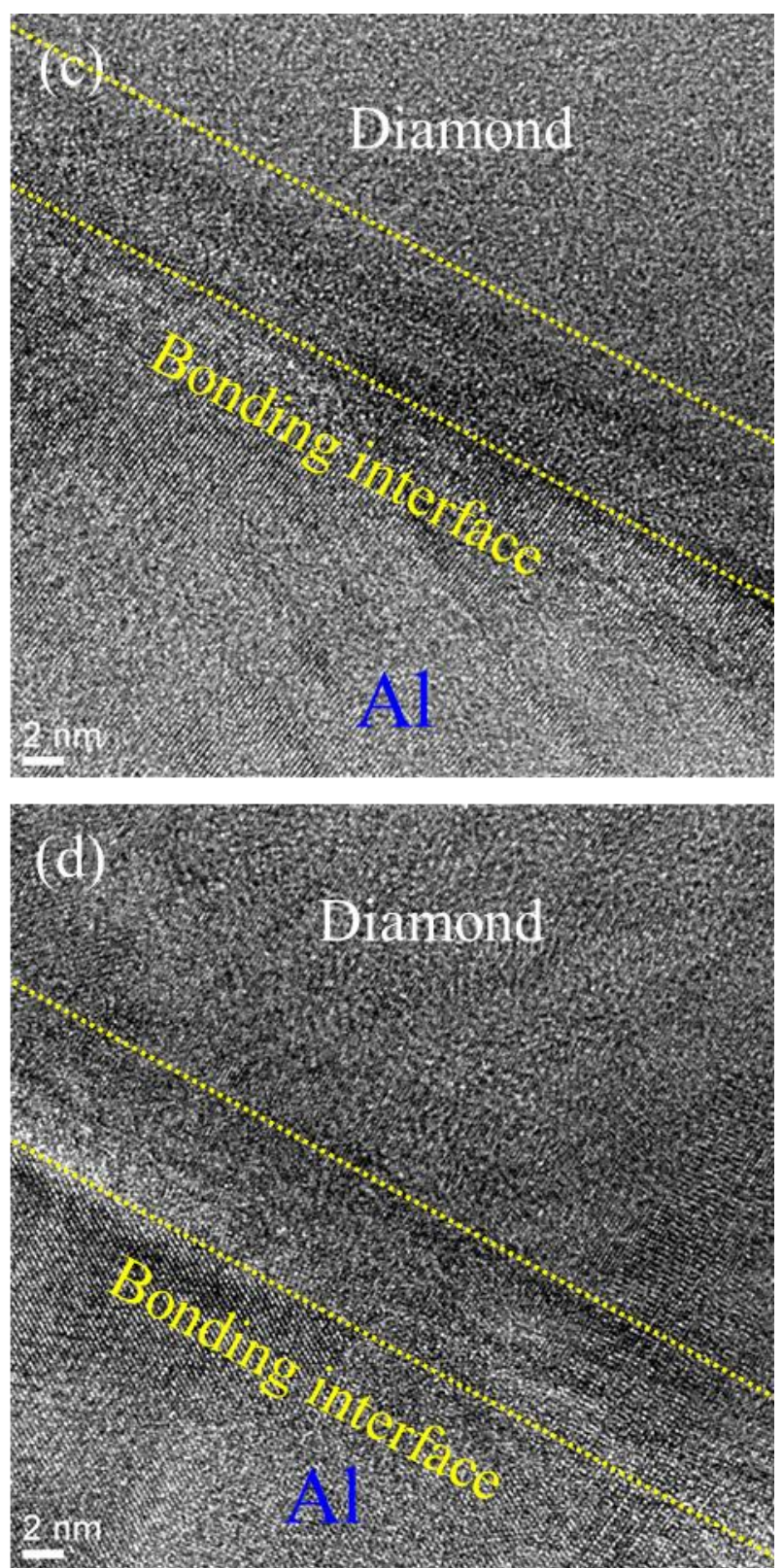

Figure 2 High magnification cross-sectional TEM images of the diamond/Al bonding interface without (a) and with annealing at 200 (b), 400 (c), $600{ }^{\circ} \mathrm{C}$ (d). The bonding interface was annealed by In-situ annealing TEM holder under high vacuum. 
(a)

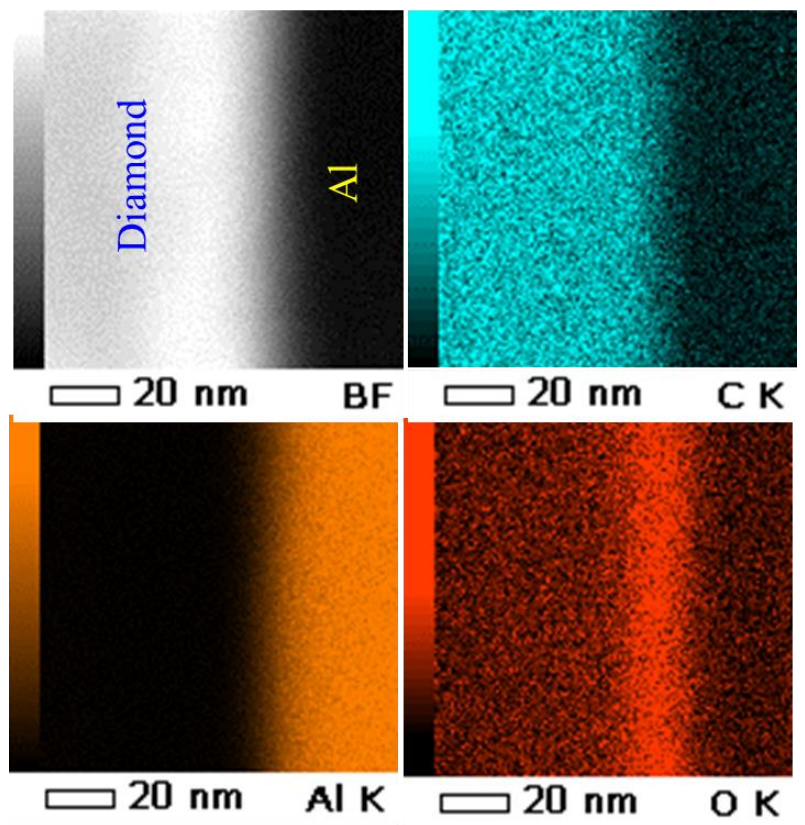

(b)

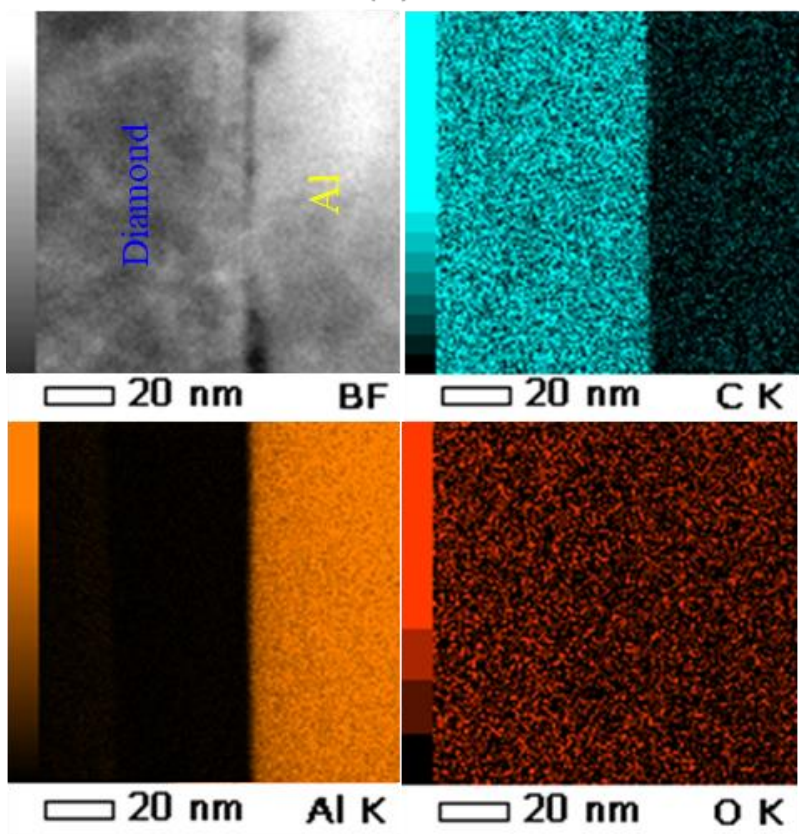

Figure 3 EDX mappings of the diamond/Al bonding interface without (a) and with annealing at $600{ }^{\circ} \mathrm{C}(\mathrm{b})$. The $\mathrm{C}, \mathrm{Al}$, and $\mathrm{O}$ element maps were highlighted in cyan, orange, and red, respectively. 
(a)

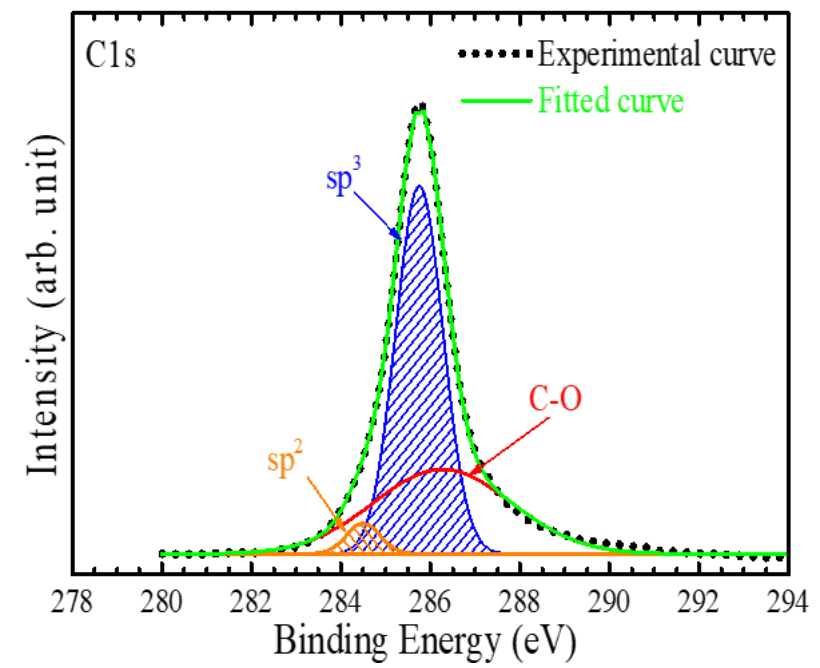

(b)

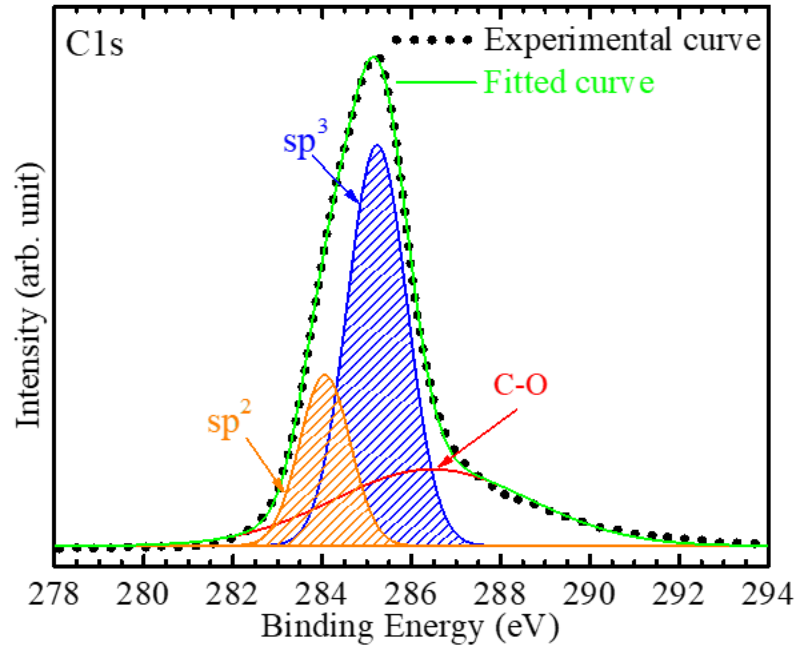

(c)

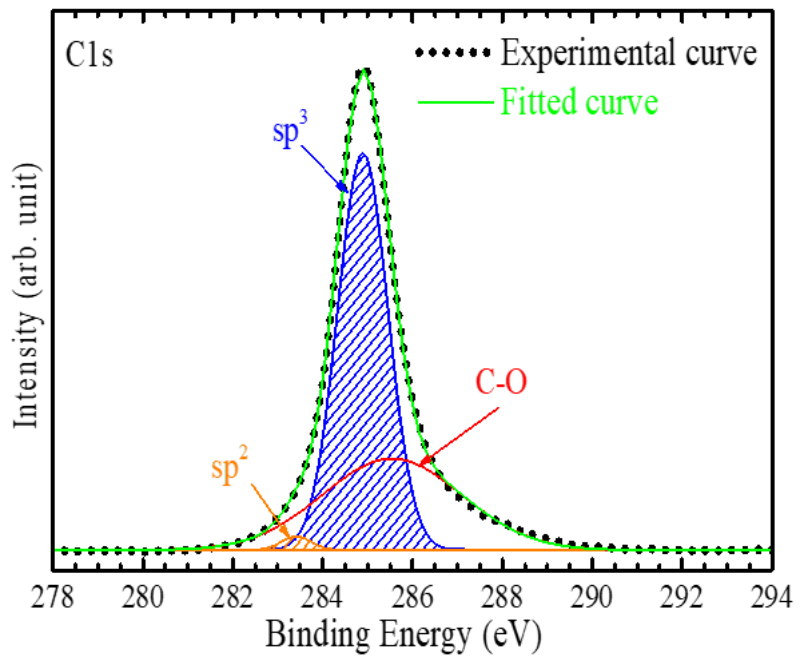




\section{(d)}

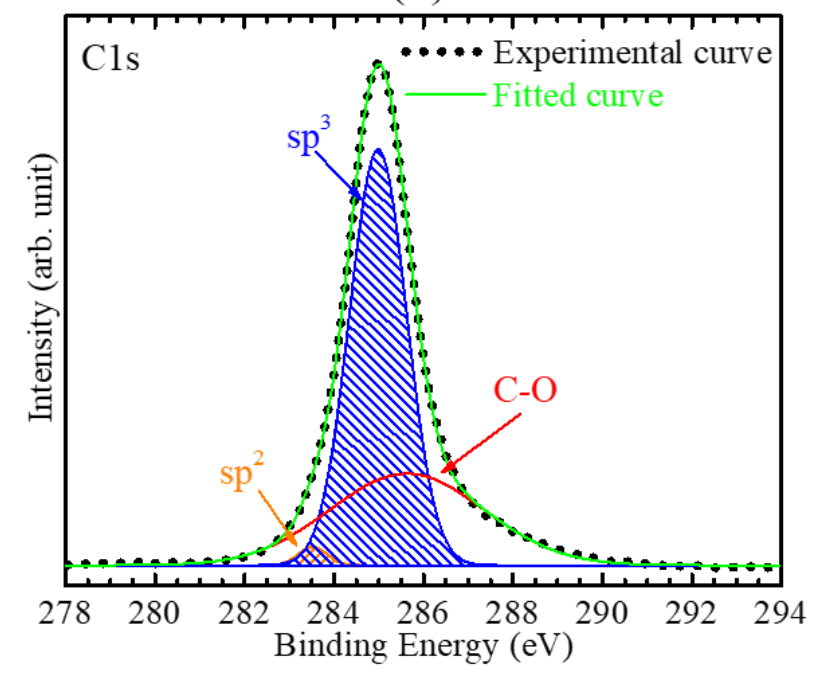

Figure 4 The C1s spectrum of diamond without (a) and with Ar irradiation (b), and with annealing at $600{ }^{\circ} \mathrm{C}$ after Ar irradiation (c), and as well as the C1s spectra of diamond of the diamond/Al bonding interface with annealing at $600{ }^{\circ} \mathrm{C}$ that was prepared by removing Al substrate by mechanical polishing and wet etching (d). 